\title{
38. RELATIVE GEOMAGNETIC INTENSITY DURING THE LAST 4 M.Y. FROM THE EQUATORIAL PACIFIC ${ }^{1}$
}

\author{
Laure Meynadier, ${ }^{2}$ Jean-Pierre Valet, ${ }^{2}$ and Nicholas J. Shackleton ${ }^{3}$
}

\begin{abstract}
A complete sequence of relative geomagnetic field intensity was obtained for the last 4 m.y. from multiple holes drilled at Sites 848,851 , and 852 (Leg 138) in the east equatorial Pacific Ocean. The time vs. depth correlation has been derived by tuning the gamma-ray attenuation porosity evaluator (GRAPE) density record (and, in some cases, the susceptibility) to the insolation curve, yielding one calibration point every $25,000 \mathrm{yr}$. Relative paleointensities were determined after normalizing the remanent magnetization of U-channels, single samples, and long core measurements by anhysteretic remanent magnetization (ARM) and low-field susceptibility $(K)$. Identical results are obtained with every technique. The composite records obtained at the three sites are very similar within their temporal resolution, which varies as a function of the deposition rates and the different sampling methods.

The most noticeable features are large decreases in field intensity accompanying the field reversals. The process is clearly asymmetrical with a long-term decrease before a transition and a rapid field recovery immediately after, thereby suggesting two different processes. Once the field has reached a maximum, it starts relaxing until the occurrence of the next reversal. Thus, the duration of the polarity intervals appears to be controlled by the field regeneration prevailing during very short episodes after major geomagnetic events, which appear themselves to result from a progressive degradation of the field. Shorter intensity minima observed during the last $2 \mathrm{~m}$.y. are correlated to geomagnetic excursions and/or short events already noticed in other data sets. This record provides a framework for a stratigraphy based on the intensity variations of the geomagnetic field.
\end{abstract}

\section{INTRODUCTION}

Most studies related to geomagnetic field variations in the past have focused on the directional changes that prevailed during reversals, excursions, and paleosecular variation. Therefore, much more is known about short- and long-term variations in field direction than in paleointensity. This is somewhat paradoxical as variations in field intensity tell us more than any other parameter about the evolution of processes governing the geodynamo. The main reason is that determinations of paleointensity are difficult and often yield unreliable results. Until recently, studies in this field were mostly obtained from archeomagnetic and volcanic materials. Archeological objects obviously are restricted in time and space. Lava flows give accurate, but discontinuous, readings for young as well as old rocks. So far, we have no other information about long-term changes in field intensity than a few scarce volcanic records.

New hope emerged recently with the publication of detailed and continuous records of relative paleointensity from sedimentary sequences (Constable, 1985; Constable and Tauxe, 1987; Tauxe and Valet, 1989; Tauxe and Wu, 1990; Tric et al., 1992). Indeed, several studies (Tauxe and Wu, 1990; Meynadier et al., 1992) showed that a good agreement existed among records from distinct sites, as well as an overall coherence among relative paleointensity, archeomagnetic, and volcanic data for the period covering the last hundred thousand years. Four records spanning a part or the entire Brunhes Chron have also been published (Kent and Opdyke, 1977; Tauxe and Wu, 1990). However, the length of these records does not allow examination of field intensity behavior across the last reversals. Dominant frequencies have been observed within the last 350 thousand years (k.y.), but there is no clear indication of whether they are truly connected to underlying processes that drive the geodynamo.

\footnotetext{
'Pisias, N.G., Mayer, L.A., Janecek, T.R., Palmer-Julson, A., and van Andel, T.H (Eds.), 1995. Proc. ODP, Sci. Results, 138: College Station, TX (Ocean Drilling Program). France.

Institut de Physique du Globe de Paris, 4 Place Jussieu, 75252 Paris Cedex 05,

Godwin Laboratory for Quaternary Research, Cambridge University, Free School Lane, Cambridge CB2 3RS, United Kingdom.
}

Among other questions that remain to be answered, is whether orbital parameters of the Earth have consequences on the fluid motions in the fluid core driving the geodynamo.

For these reasons, we attempted to obtain a long paleointensity record that spanned the last 3 or $4 \mathrm{Ma}$. Except for zones having very low deposition rates, which are useless for the present study, conventional piston cores do not provide sequences of sediment long enough to document the field variations during these periods. The Ocean Drilling Program offers the only opportunity for retrieving long sequences of sediment. The sites drilled during Leg 138 were appropriate because they mostly are located close to the equator, with mean deposition rates between 1.5 and $3 \mathrm{~cm} / \mathrm{k}$.y. (i.e., large enough to record variations with characteristic times on the order of a few thousand years). Finally, the distribution of the sites, along two parallel latitudinal transects, separated by relatively large distances, was appropriate to average out most of the effects of any possible nondipole components.

\section{SAMPLING, CORRELATION, AND DATING}

Sites 848,851 , and 852 (Fig. 1) were selected for this study on the basis of the magnetostratigraphic results obtained from the shipboard measurements (see Leg 138 Initial Reports volume). The results from Site 848 show the succession of all polarity intervals back to the Gilbert Epoch. Site 851 is characterized by the highest deposition rates with an average value of $1.8 \mathrm{~cm} / \mathrm{k}$.y. for the last $4 \mathrm{Ma}$ (Shackleton et al., 1992). Site 852 provided one of the longest records, with excellent magnetostratigraphy, but with resolution lower than that at the other sites by at least a factor of two. Because more than three distinct holes had been drilled at Sites 848 and 851 , we were able to sample Cores $1 \mathrm{H}, 2 \mathrm{H}$, and $3 \mathrm{H}$ from Hole $848 \mathrm{D}$ and Cores $1 \mathrm{H}$ and $2 \mathrm{H}$ from Hole 851D with U-channels (Tauxe et al., 1983). A total of 657 complementary standard paleomagnetic cubic samples were taken from Cores $138-848 \mathrm{C}-2 \mathrm{H}$ to $3 \mathrm{H}, 138-848 \mathrm{D}-4 \mathrm{H}$ to $5 \mathrm{H}, 138-851 \mathrm{C}-1 \mathrm{H}, 138-851 \mathrm{E}-$ $2 \mathrm{H}$ to $8 \mathrm{H}, 852 \mathrm{D}-1 \mathrm{H}$ to $7 \mathrm{H}$ (1) to fill the gaps between successive cores, (2) to provide independent checks about the spatial resolution of the U-channels, and/or (3) to check the magnetic properties of the sediment (Fig. 2). 


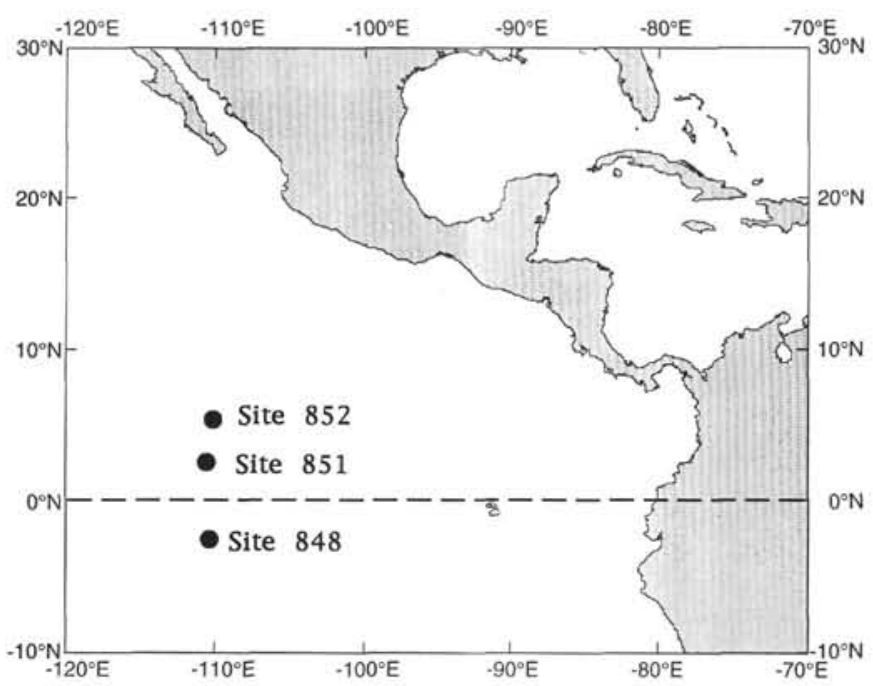

Figure 1. Geographic location of the three Leg 138 sites involved in this study.

Correlation among holes is based on composite depths established from shipboard measurements by combining data from GRAPE density, low-field magnetic susceptibility, and color reflectance (Hagelberg et al., 1992). Despite the great care taken for this correlation, some small discrepancies still were present between adjacent holes. These were mostly the consequence of sediment stretching. These differences were taken into account by adjusting the sequences after calculating a linear correction of the depths. The final results show identical variations between holes. No susceptibility record was mea-sured in the upper part of the cores from Holes 851E and 851D, and the composite records at these levels had been established from the density variations. However, the color reflectance and the susceptibility records indicated that Core $138-851 \mathrm{C}-1 \mathrm{H}$ should start $1.5 \mathrm{~m}$ above the composite depths (mcd) established on board the ship. Thus, we changed the mods of Core $1 \mathrm{H}$ from Holes $851 \mathrm{~A}, 851 \mathrm{~B}$, $851 \mathrm{D}$ and $851 \mathrm{E}$ by adding $1.5 \mathrm{~m}$.

Dating was provided by orbital tuning of the GRAPE density stratigraphy measured on board the ship (Shackleton et al., 1992; Shackleton et al., this volume). As the major source of density variations is changing carbonate content, the signal has been tuned to changes in insolation. On average, this method gave a calibration point about every 25 k.y. The magnetic susceptibility at Site 851 is mostly sensitive to changes in dilution induced by variations of the carbonate fraction. Thus, we used this parameter to obtain a detailed depth vs. time correspondence for the U-channels of Cores $1 \mathrm{H}$ and $2 \mathrm{H}$ from Hole $851 \mathrm{D}$. We correlated the susceptibility to the SPECMAP record (Imbrie et al., 1984) down to $0.6 \mathrm{Ma}$ and to the $\delta^{18} \mathrm{O}$ record obtained from Core MD900963 (Indian Ocean) down to stage 22. This last record was tuned to the insolation curve (Bassinot et al., in press) with the technique used by Shackleton et al. (1990) at Site 677. Below this level, we used the GRAPE density time vs. depth correlation established by Shackleton et al. (1994).

\section{MEASUREMENTS}

Measurements were performed in the shielded room of the Institut de Physique du Globe de Paris by using a $2 \mathrm{G}$ three-axis cryogenic magnetometer equipped with two pick-up coil systems (high resolution and high homogeneity) and a Bartington susceptibility meter mounted in line with the magnetometer. We essentially followed the procedure described elsewhere (Nagy and Valet, 1993) for a complete paleomagnetic study of U-channels of sediment cores. These techniques involve measurements spaced every $2 \mathrm{~cm}$ using the highresolution pick-up coils of the magnetometer, complete stepwise alter- nating field (AF) demagnetization (eight steps, at least up to $90 \mathrm{mT}$ ), analysis of the demagnetization data, and study of the rock magnetic parameters $(K$, anhysteretic remanent magnetization [ARM] obtained in a $0.05-\mathrm{mT}$ direct field and $80 \mathrm{mT} \mathrm{AF}$, and isothermal remanent magnetization [IRM]) with their related ratios.

Figure $3 \mathrm{~A}$ shows results of the measurements of a typical U-channel from Core 138-851D-1H. We plotted the downcore evolution of the remanent intensity, the angular dispersion of directions between successive demagnetization steps, and the downcore changes in the rate of intensity decrease between two steps of demagnetization (RID). We also examined the variations in concentration of magnetic materials revealed by the downcore changes in $K, \mathrm{ARM}$, and $\mathrm{IRM}_{(1.2 \mathrm{~T})}$ (IRM acquired in a field of $1.2 \mathrm{~T}$ ), the evolution of the magnetic grain sizes by using the $\mathrm{ARM} / K$ ratio, and changes in magnetic mineralogy by using the S-ratio (defined as $-\mathrm{IRM}_{(-0.3 \mathrm{~T})} / \mathrm{IRM}_{(1.2 \mathrm{~T})}$ ) (Stober and Thompson, 1979). A typical example is shown in Figure 3B, for U-channels $138-848 \mathrm{D}-1 \mathrm{H}$ and $-2 \mathrm{H}$. The combination of these plots allowed us to observe changes in behavior upon demagnetization and variations in rock magnetic properties.

Magnetic homogeneity of the sediment is a fundamental and basic condition for reliable determinations of paleointensity. In the present case, all the parameters show a remarkable constancy, except within some intervals characterized by sharp and large variations, which appear to be the result of large decreases in magnetization intensity (mostly because of the absence of magnetic material). This situation was encountered for the upper $10 \mathrm{~m}$ of Site 848 (Fig. 3B) and at a very few levels of Site 851 . Other than these minor intervals, the magnetic parameters indicate that no major changes in concentration occur. The $\mathrm{S}$ ratio does not drop below 0.9 , which indicates that magnetite is the main, if not the only, carrier of magnetization. Finally, the grain size does not vary by more than a factor of three, which we think is the value that assures that the sediment is magnetically homogeneous and suitable for paleointensity studies (Meynadier et al., 1992). Sharp peaks were observed occasionally; most of these were the result of noise from external origin and were removed from the results.

More than 500 single samples were stepwise demagnetized and measured in a way similar to the U-channels. Batches of 10 samples were positioned successively along the length of the U-channel holder and completely demagnetized with 7 to 11 steps up to a peak AF field of $80 \mathrm{mT}$. With this technique, the magnetization components of all the samples could be analyzed carefully without using pilot specimens and blanket demagnetization. The study was completed by the analysis of the same rock magnetic parameters used for U-channels. Magnetic low-field susceptibility was measured with the Jelinek susceptibility bridge of the laboratory of Parc Saint Maur. The demagnetization diagrams obviously show the same characteristics as U-channels. In most cases, a first component of very low coercivity carries the overprint induced by coring, which is removed at between 10 and $15 \mathrm{mT}$. Beyond this step, the magnetization of the samples shows univectorial behavior. Overall, the demagnetization diagrams are of very good to excellent quality; less than $1 \%$ of the samples were rejected, mostly because of their low magnetization intensity.

Since different sets of measurements were performed at each site, we were able to compare directly the results obtained with single samples, U-channels, and long core measurements by using the ARM and the low-field susceptibility as normalization parameters of the magnetic field intensity. Such comparisons allowed us to check the reproducibility and the coherence between holes.

In Figure 4, we compare the shipboard measurements of the NRM of cores from Site 852, demagnetized at $15 \mathrm{mT}$ and normalized by the low-field susceptibility $\left(\mathrm{NRM}_{(15 \mathrm{mT})} / K\right)$, with those of the single samples, demagnetized at $20 \mathrm{mT}$ and normalized by ARM demagnetized at the same level $\left(\mathrm{NRM}_{(20 \mathrm{mT})} / \mathrm{ARM}_{(20 \mathrm{mT})}\right)$. At Sites 848 and 851 , we can also compare the same two ratios for cores and samples with the NRM of U-channels demagnetized at $20 \mathrm{mT}$ and normalized by ARM demagnetized at the same level $\left(\mathrm{NRM}_{(20 \mathrm{mT})} / \mathrm{ARM}_{(20 \mathrm{mT})}\right.$ ) (no Uchannels could be taken at Site 852). 

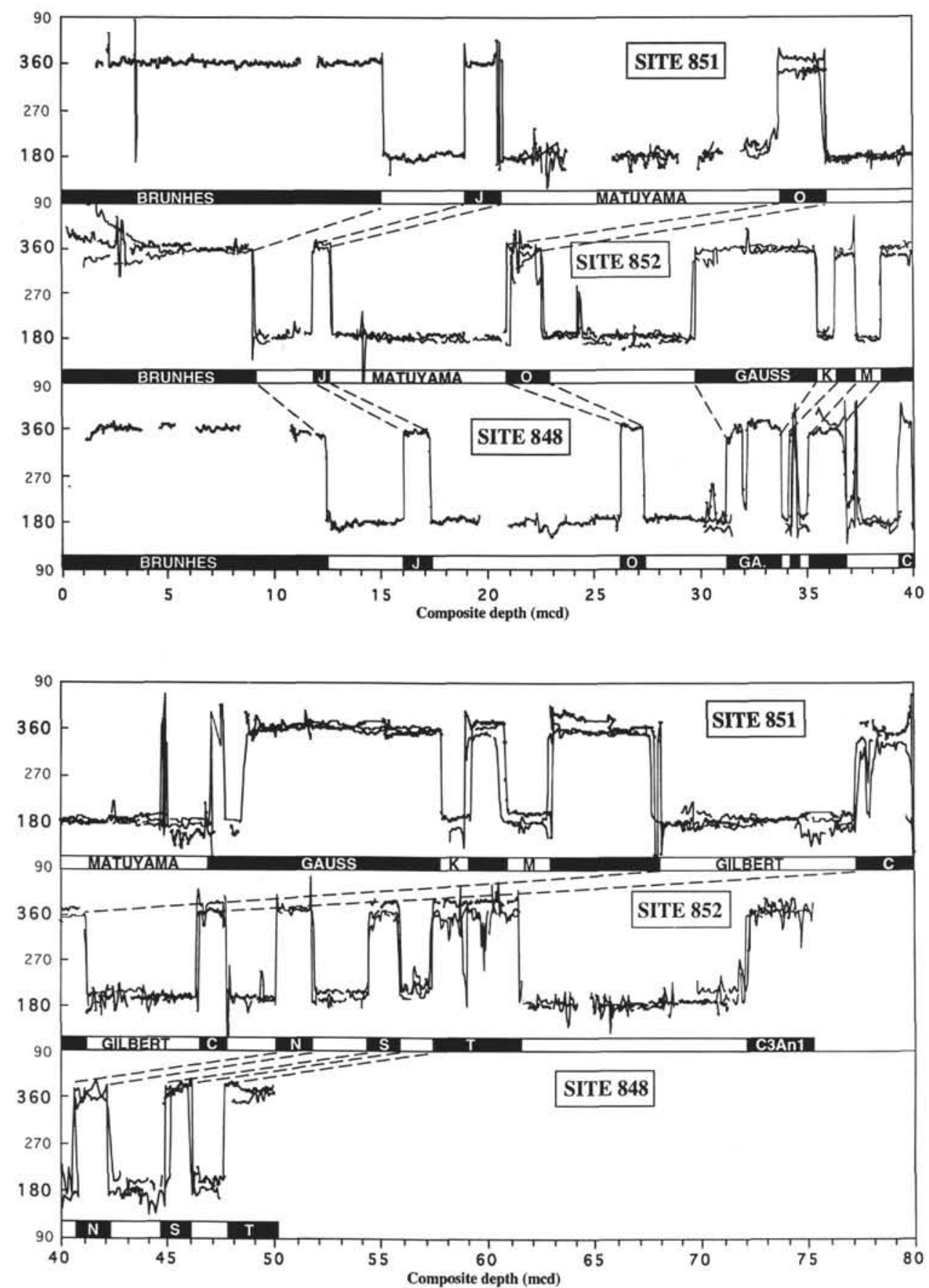

Figure 2. Magnetostratigraphy obtained at the three sites from U-channel, single sample, and long-core shipboard measurements. The data shown are declination vs. composite depth (mcd). Site 851: 0-21 mcd: U-channels Hole 851D; 21-80 mcd: shipboard measurements Holes 851B, 851C, and 851E. Site 852: 0-75 mcd: shipboard measurement Holes 852A, 852B, 852C, and 852D. Site 848: 0-30 mcd: U-channels Hole 848D; 30-50 mcd: shipboard measurements Holes 848B, 848C, and 848D. J. = Jaramillo, O. = Olduvai, GA. = Gauss, K. = Kaena, $\mathrm{M} .=$ Mammoth, $\mathrm{C} .=$ Cochiti, $\mathrm{N} .=$ Nunivak, $\mathrm{S} .=$ Sidufjall, and $\mathrm{T} .=$ Thvera.

All of these results show that independent parameters related to magnetic concentration display the same features, within the limit of spatial resolution inherent to the methods used for the measurements (for example, the single cubes were sampled every 10 to $15 \mathrm{~cm}$ ). A direct consequence is that the $\mathrm{NRM} / K$ ratio of the shipboard long core measurements can be used as well as the NRM/ARM of the Uchannels and the single samples to reconstruct the relative paleointensity. However, the spatial resolution provided by U-channels is much higher, and we always rely on these measurements when they are available. Table 1 gives a complete summary of the different kinds of measurements performed at each site.

\section{RESULTS \\ Coherency Between Sites}

As explained above, the composite paleointensity record at each site includes the $\mathrm{NRM}_{(20 \mathrm{mT})} / \mathrm{ARM}_{(20 \mathrm{mT})}$ ratios from U-channels for the first two or three cores (except at Site 852). Below the stratigraphic 
A

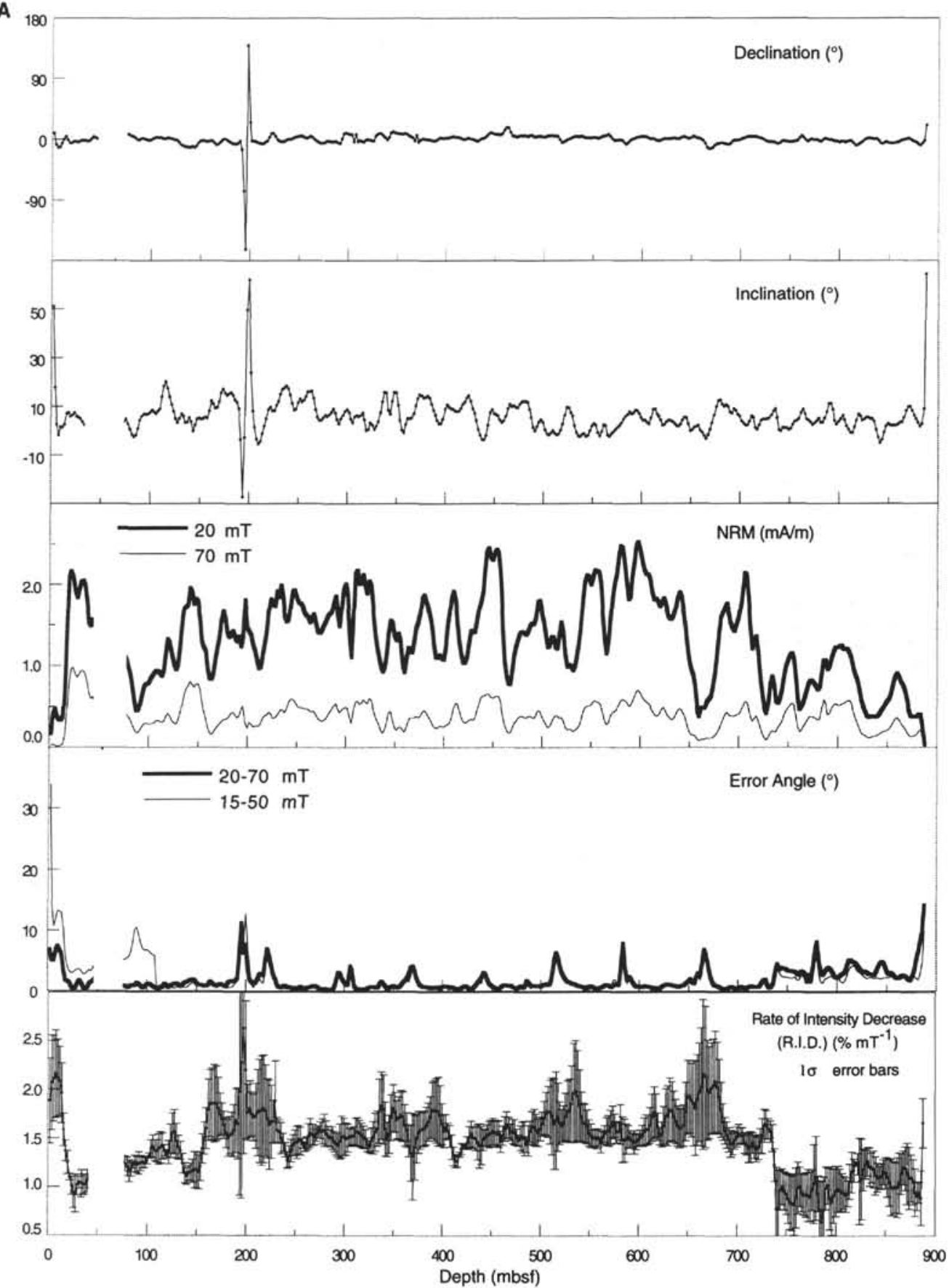

Figure 3. Typical parameters used for U-channel measurements. A. An example of U-channel is shown: 138-851D-1H. Measurements were performed every $2 \mathrm{~cm}$. Declinations (D) and inclinations (I) were calculated by fitting a least-squares line, anchored to the origin, to data points corresponding to at least five successive demagnetization steps between 20 and $70 \mathrm{mT}$. Magnetic intensities are shown as measured, following both of these demagnetization steps. Least-squares calculations of $\mathrm{D}$ and $\mathrm{I}$ have been repeated several times over different ranges of demagnetization steps, together with the corresponding error angles. Rate of intensity decrease (RID; with its standard deviation) represents the slope of the AF demagnetization curve, here between 20 and $70 \mathrm{mT}$, normalized by the initial value of NRM (here, $20 \mathrm{mT}$ ). This calculation has been applied to every successive measurement position. The selection of demagnetization steps used for the final calculation of the characteristic component of magnetization was determined after scrutinizing these parameters. B. Characteristic rock-magnetic parameters used for disregarding intervals unsuitable for paleointensity in U-channels (shown for Cores 138-848D-1H and -2H). These intervals are shown as hachured zones. 
B

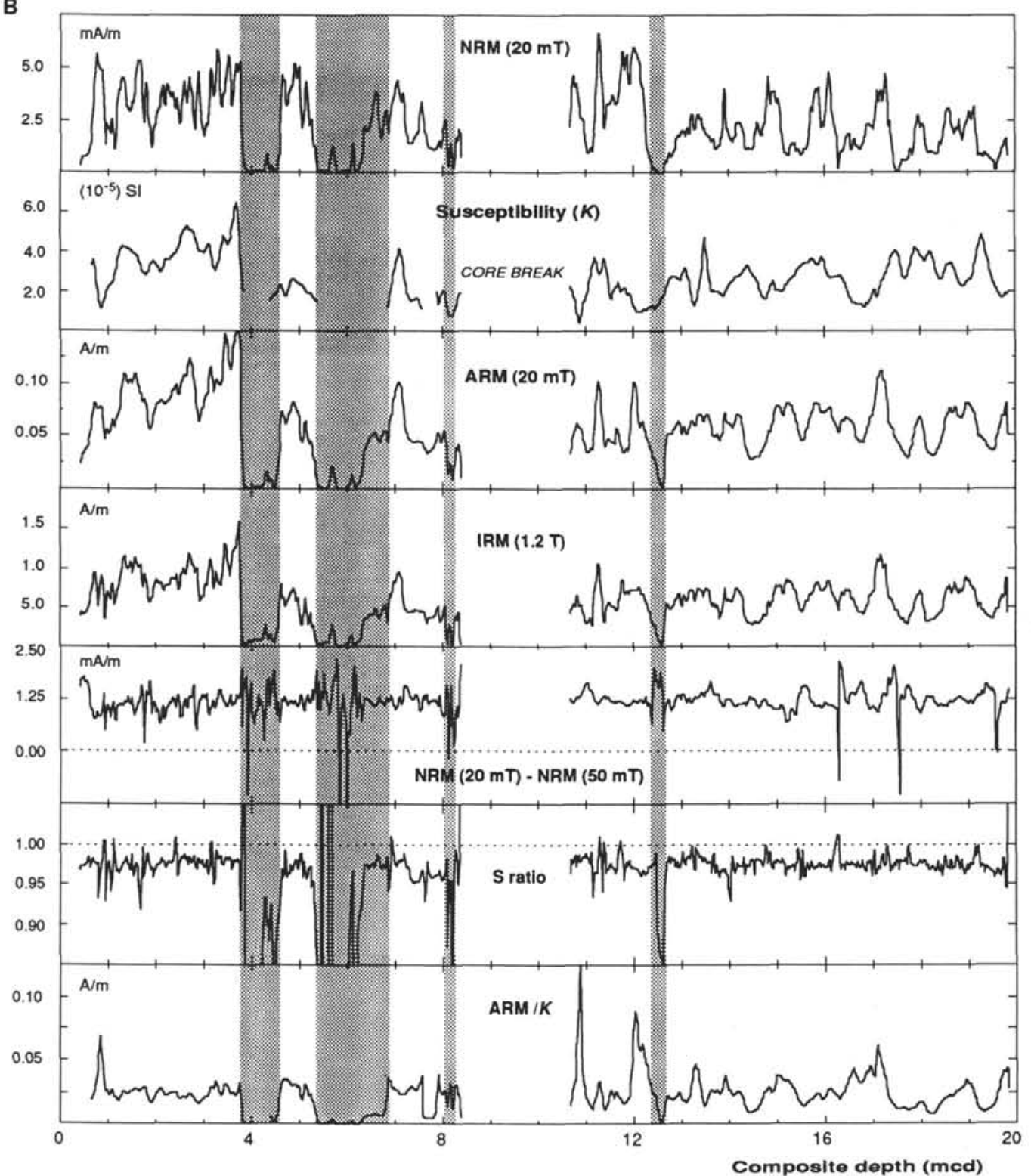

Figure 3 (continued).

intervals sampled by U-channels, we averaged the values of $\mathrm{NRM}_{(15 \mathrm{mT})} / K$ between the same levels of the two, three, or four holes studied at the site. Therefore, these results incorporate data from Holes 848A, 848B, 848C, 848D, 851A, 851B, 851C, 851D, 852A, $852 \mathrm{~B}, 852 \mathrm{C}$, and $852 \mathrm{D}$. Matching between these two distinct ratios was performed after calculating the downhole mean values of $\mathrm{NRM}_{(20 \mathrm{mT})} / \mathrm{ARM}_{(20 \mathrm{mT})}$ and $\mathrm{NRM}_{(15 \mathrm{mT})} / K$. No other correction was applied to the results.

The final records obtained at each site are shown in Figures 5A, $5 \mathrm{~B}$, and $5 \mathrm{C}$ as a function of time. These signals are similar for the three sites within their respective resolution, which depends on deposition rates and the response curves of the instruments used for continuous measurements. For example, the upper part of Site 852 has an average deposition rate about twice as low as that at Site 851, and no $\mathrm{U}$-channel could be measured; thus, this part of the record must be seen as the convolution of the signals obtained at the other sites. The lower part of Site 852 has more or less the same resolution as that at Site 851 and correlates well except for some short intervals. The upper parts of the records from Sites 848 and 851 also are very similar, but an abrupt change by a factor of 2.5 is seen in the deposi- tion rate at Site 848 at $1.5 \mathrm{Ma}$. Consequently, the rest of this record is much less detailed; before the Gauss/Matuyama boundary, the record is so heavily smoothed that only long wavelength features have persisted. Because of the absence of magnetization within some intervals, no continuous record could be obtained for the entire Brunhes period from the U-channels and the cores from Site 848; we note, however, that good coherence exists between the magnetized intervals from this site and the record obtained at Site 851. The most coherent features at the three sites are the large declines in intensity associated with the geomagnetic reversals, which we see as a strong indication of the geomagnetic signature of the signal.

\section{Composite Record}

In Figure 6, we show successive plots of the directional changes and relative paleointensities between 0 and $3.8 \mathrm{Ma}$. Every plot has been drawn from the results obtained with the best temporal resolution. A synthetic curve was obtained from spliced sections within the most detailed parts of the records. We preferred this method to a stack, which would have resulted in a lower resolution. Thus, this curve 

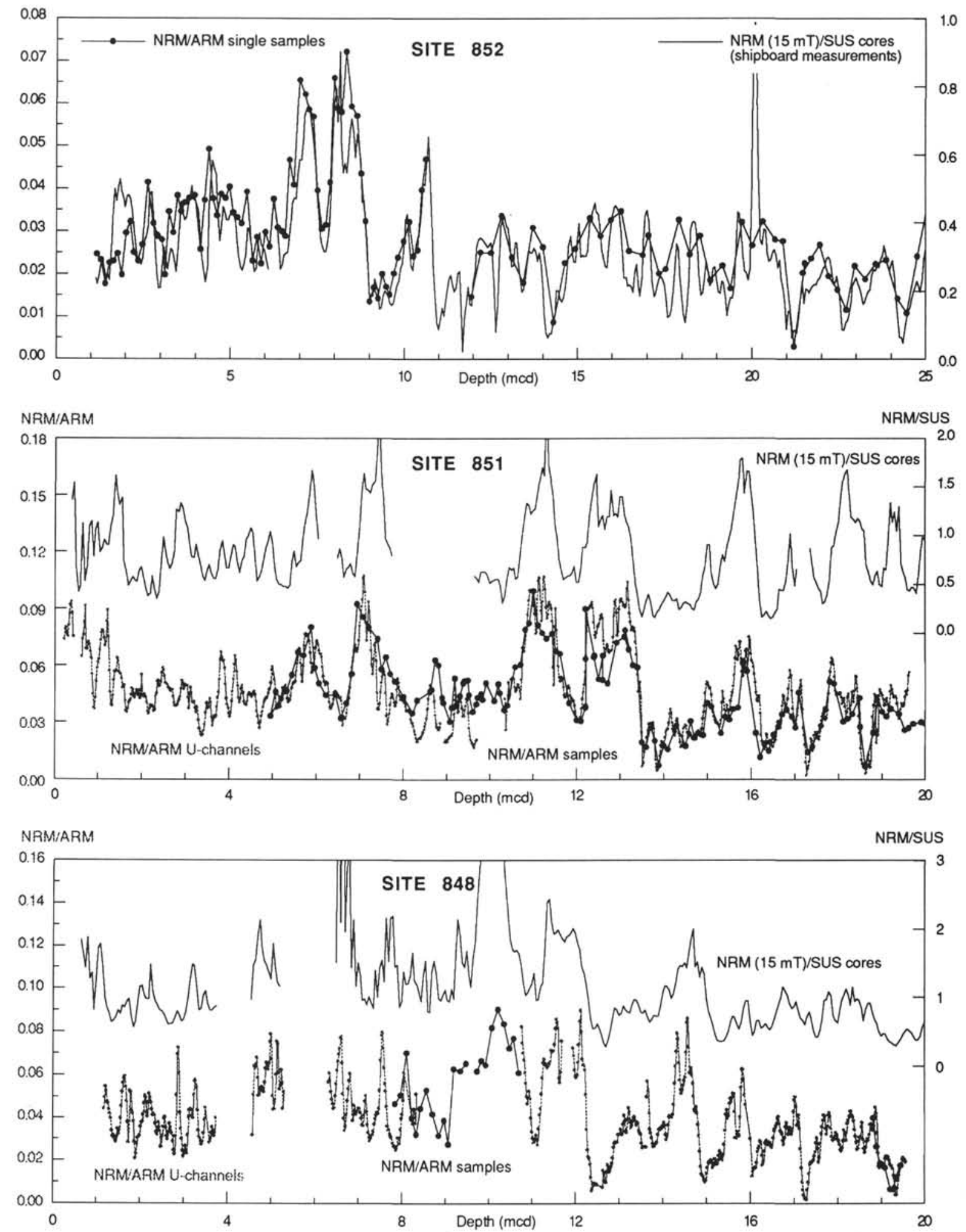

Figure 4. Comparison between the paleointensity records obtained at Holes 848,851 , and 852 from measurements of single samples, long cores, and U-channels. Better resolution and results are provided by the NRM/ARM from U-channels; this technique is always preferred.

(shown in Fig. 7) is composed of data from Sites 848 and 851 and retraces the relative variations of field intensity for the last $4 \mathrm{Ma}$ (Table 2).

One of the major problems with relative paleointensity estimates from sediments is that they must be independent of rock magnetic parameters linked to paleoclimatic variations. A first characteristic is that the main features displayed by the current records clearly are correlated with major geomagnetic events. Another aspect is that the $\mathrm{NRM}_{(20 \mathrm{mT})}$ and the other parameters are strikingly different. Since the downcore variations in the ARM or susceptibility are relatively small compared to the changes in $\mathrm{NRM}_{(20 \mathrm{mT})}$, they certainly do not have a major influence on the final record. However, normalization could 

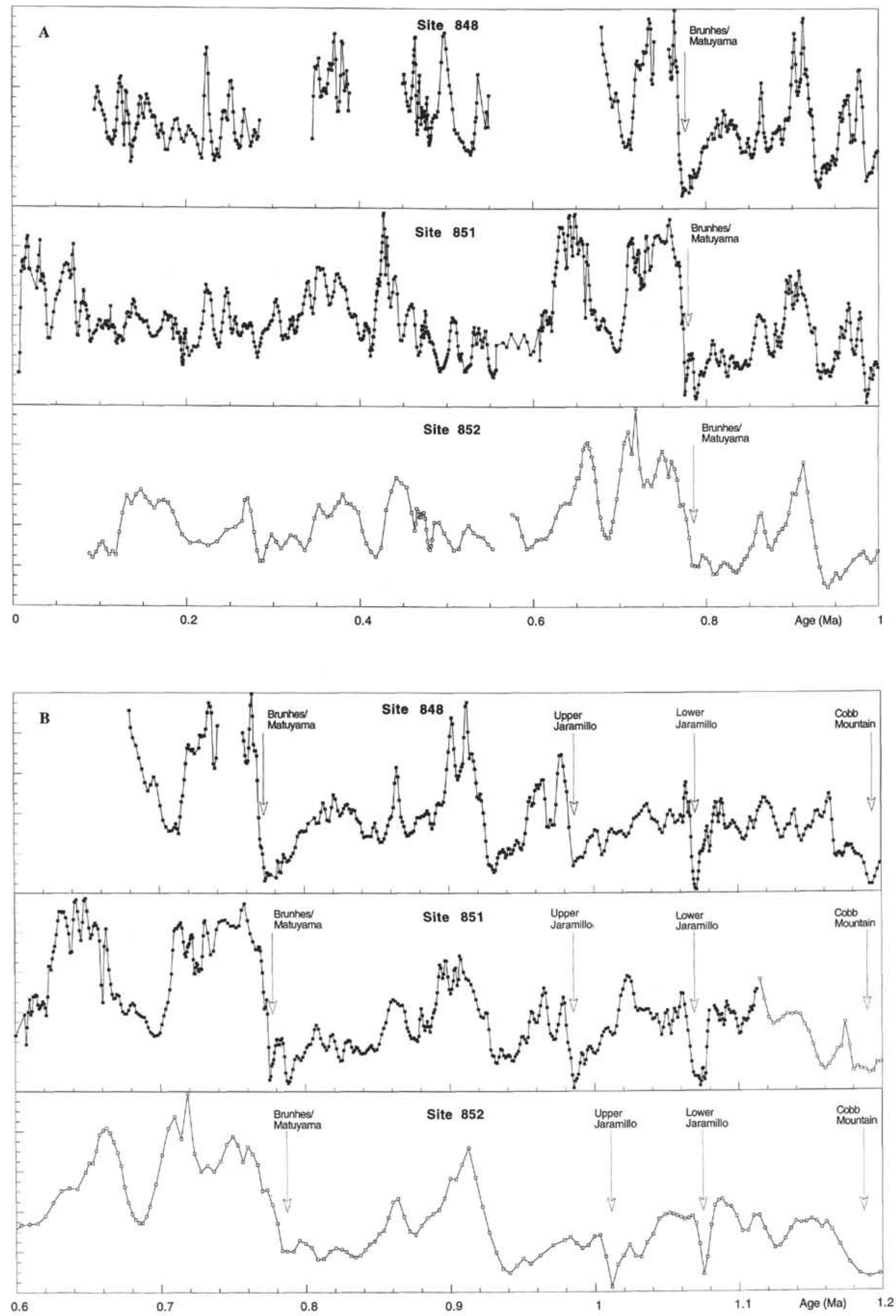

Figure 5. Composite records of relative paleointensity obtained at every site from the $\mathrm{NRM}_{(20 \mathrm{mT})} / \mathrm{ARM}_{(20 \mathrm{mT})}$ ratios measured on U-channels (closed symbols) and the $\mathrm{NRM}_{(15 \mathrm{mT})} / K$ (low-field susceptibility) ratios deduced from the shipboard long-core measurements (open symbols). 


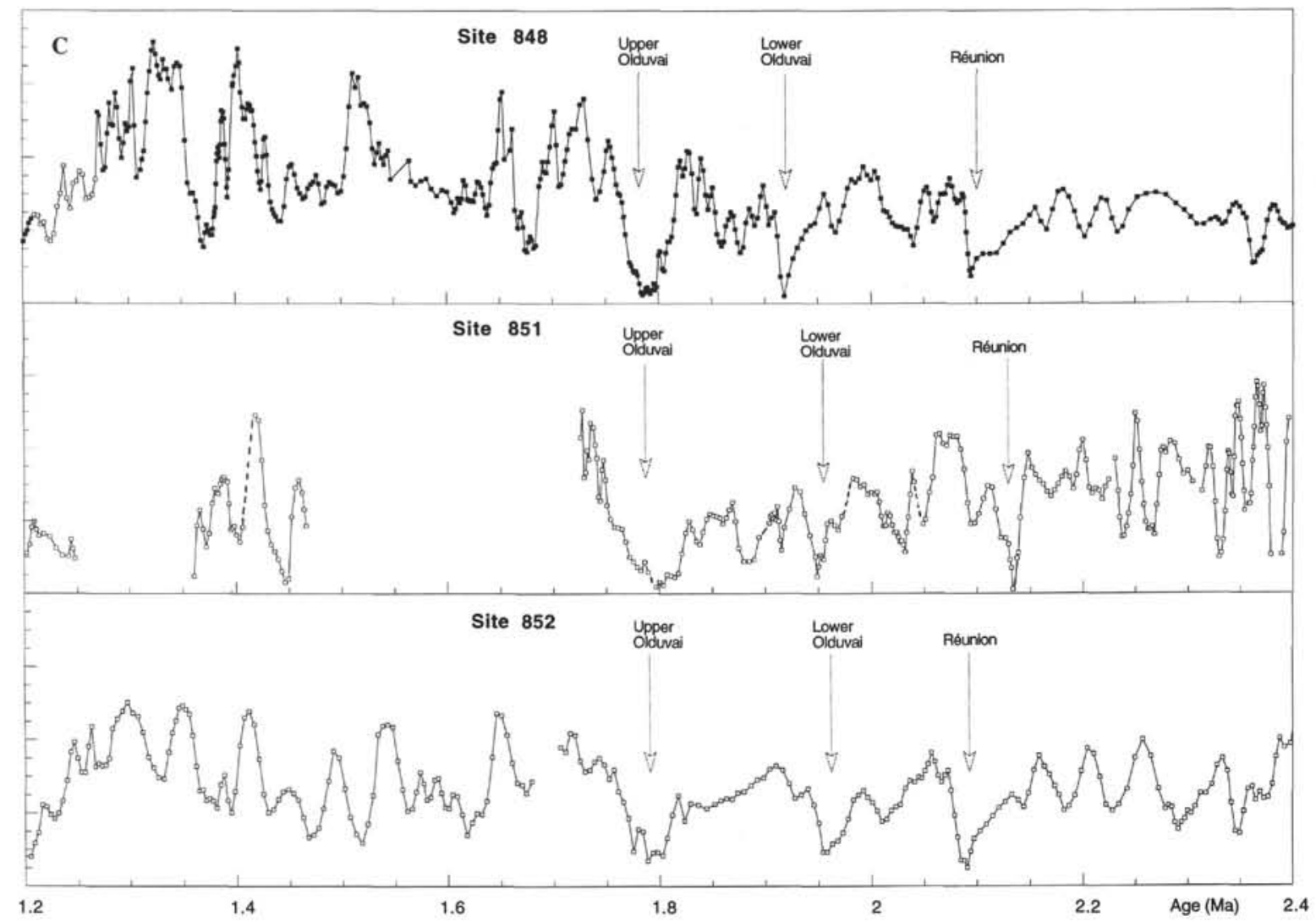

Figure 5 (continued).

Table 1. Summary of the different kinds of measurements performed at each site.

\begin{tabular}{|c|c|c|c|}
\hline Site & $\begin{array}{c}\text { U-channels } \\
\text { NRM/ARM } \\
\text { (AF demag. at } 20 \mathrm{mT} \text { ) }\end{array}$ & $\begin{array}{l}\text { Archive halves of cores } \\
\text { NRM/Susceptibility } \\
\text { (AF demag. at } 15 \mathrm{mT} \text { ) }\end{array}$ & $\begin{array}{c}\text { Single samples } \\
\text { NRM/ARM } \\
\text { (AF demag. at } 20 \mathrm{mT} \text { ) }\end{array}$ \\
\hline 852 & None & $\begin{array}{l}852 \mathrm{~A} \\
852 \mathrm{~B} \\
852 \mathrm{C} \\
852 \mathrm{D}\end{array}$ & $138-852 \mathrm{D}-1 \mathrm{H}$ to $-3 \mathrm{H}$ \\
\hline 851 & $\begin{array}{l}\text { 138-851D-1H } \\
138-851 \mathrm{D}-2 \mathrm{H}\end{array}$ & $\begin{array}{l}851 \mathrm{~A} \\
851 \mathrm{~B} \\
851 \mathrm{C}\end{array}$ & $\begin{array}{l}138-851 \mathrm{C}-1 \mathrm{H} \\
138-851 \mathrm{E}-1 \mathrm{H} \text { to }-8 \mathrm{H}\end{array}$ \\
\hline 848 & $\begin{array}{l}138-848 \mathrm{D}-1 \mathrm{H} \\
138-848 \mathrm{D}-2 \mathrm{H} \\
138-848 \mathrm{D}-3 \mathrm{H}\end{array}$ & $\begin{array}{l}848 \mathrm{~A} \\
848 \mathrm{~B} \\
848 \mathrm{C} \\
848 \mathrm{D}\end{array}$ & $\begin{array}{l}138-848 \mathrm{C}-2 \mathrm{H} \text { and }-3 \mathrm{H} \\
138-848 \mathrm{D}-4 \mathrm{H} \text { and }-5 \mathrm{H}\end{array}$ \\
\hline
\end{tabular}

have introduced artificial components in the range of the dominant frequencies related to the climatic variations. In Figure 8, we have plotted the downhole evolution of low-field susceptibility, GRAPE density records, and our best estimate of relative paleointensity based on the $\mathrm{NRM}_{(20 \mathrm{mT})} / \mathrm{ARM}_{(20 \mathrm{mT})}$ ratio. Except for the Grape density record, all these parameters were measured from the U-channels of Hole 851D, and they do not appear to be correlated. This conclusion is confirmed by the plots of susceptibility and density vs. $\mathrm{NRM}_{(20 \mathrm{mT})} /$ $\mathrm{ARM}_{(20 \mathrm{mT})}$. We are aware that other subtle influences of lithologic factors are possible. However, these factors would not be involved in the long-term variations which are the primary focus in this study.
Our paleointensity record should agree with the absolute data sets obtained from volcanics and archeomagnetic materials. All the drilling sites are located more or less at the same low latitudes; thus, it is valid to compare directly between the raw magnetic field intensities deduced from this study and virtual axial dipole moments. This approach was followed by Tric et al. (1992), who found an excellent fit between the relative variations in the sedimentary records from the Mediterranean Sea and the absolute values from volcanics for the period 0 to 80 k.y.. The same calibration in terms of virtual axial dipole moments (VADM) was used by Meynadier et al. (1992) in their study of records from the Somali Basin, which duplicate the variations recorded in the Mediterranean Sea for the period 0 to 80 k.y. and extend the curve back to 140 k.y. ago. There is variation by at least a factor of 2 and at most a factor of 10 between the resolutions of these data sets and the resolution of the present records from the Pacific Ocean. No reliable paleomagnetic record could be obtained from the upper parts of the ODP cores because of disturbances that resulted from coring. Consequently, they could not be used for comparison with the absolute values for the last 50 k.y.. However, we were able to calibrate the records by using the composite curves published for the Mediterranean Sea and Indian Ocean. This calibration could then be compared to the absolute paleointensities expressed in terms of virtual dipole moments (VDMs), obtained recently from the Eifel Volcanic Sequence in Germany, which cover the interval between 0.45 and 0.65 Ma (Fig. 9; Schnepp, 1992, 1994; Schnepp and Hradetzky, unpubl. data). No intermediate direction was observed in our record for that period and, therefore, VDMs are similar to the VADMs. The Eifel VDMs are in agreement with the low relative paleointensities observed during this period. However, the volcanic VDMs shown in Figure 9 with opened circles are associated with low latitudes of the virtual geomagnetic pole (VGP) and thus could represent large paleosecular variation or excursional directions 

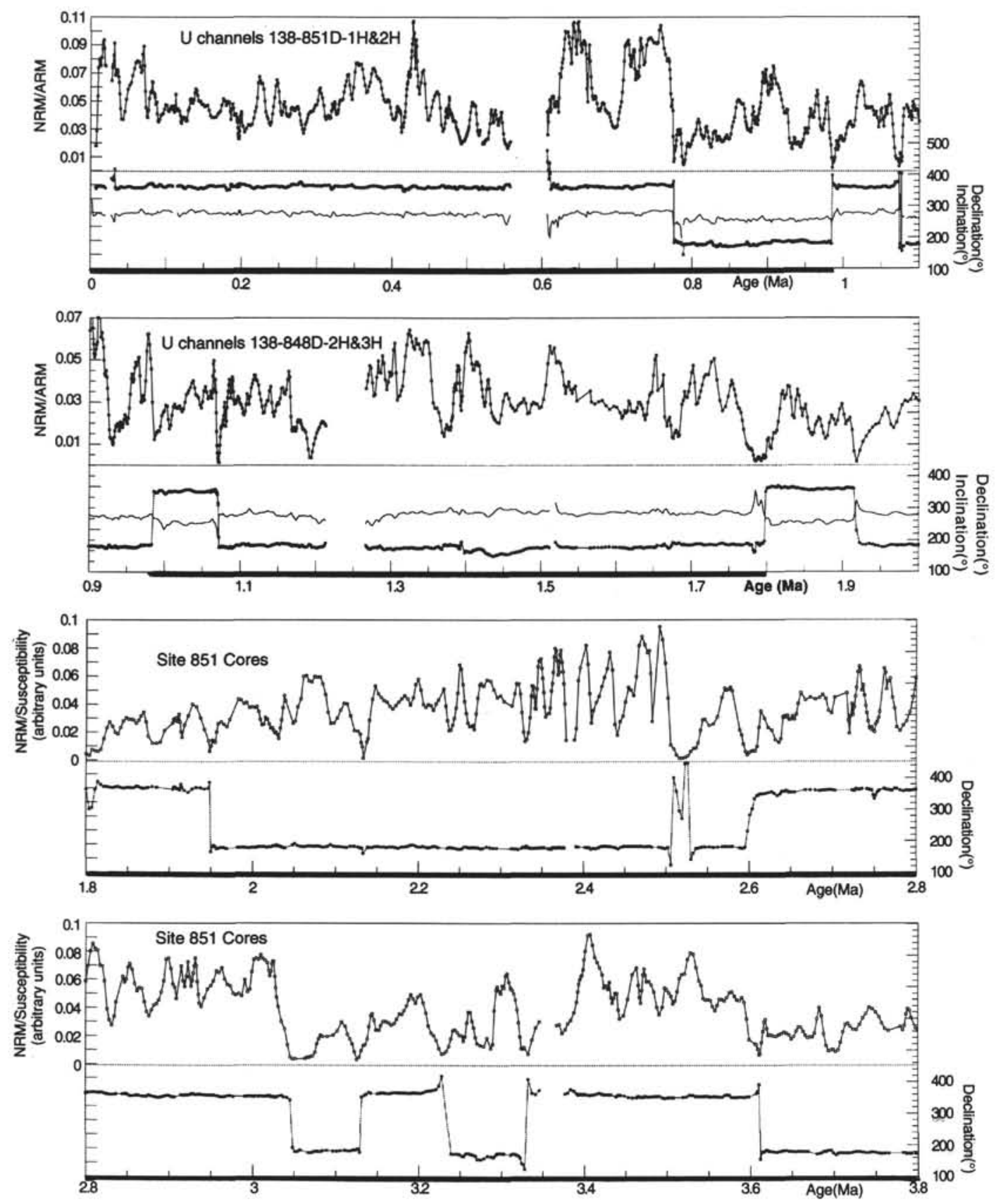

Figure 6. Records of relative paleointensity and directional changes from sequences characterized by the best temporal resolution. The values of inclination have been added to $270^{\circ}$ for plotting on a common scale with the declination (therefore $0^{\circ}$ inclination $=270^{\circ}$ ). Composite splices used in the construction of the synthetic curve are shown by dark lines at the bottom of every plot (and summarized in Table 2).

Table 2. Construction of the composite record (see Figs. 6 and 7).

\begin{tabular}{|c|c|c|c|}
\hline \multicolumn{4}{|c|}{ Composite and final record } \\
\hline Hole & & Begins at & Ends at \\
\hline 851D & U-channels & $0 \mathrm{Ma}$ & upper Jaramillo (0.99 Ma) \\
\hline $848 \mathrm{D}$ & U-channels & upper Jaramillo (0.99 Ma) & upper Olduvai (1.8 Ma) \\
\hline $851 \mathrm{~B}$ and $851 \mathrm{C}$ & Long cores & upper Olduvai (1.8 Ma) & End of the record ( $4 \mathrm{Ma})$ \\
\hline
\end{tabular}




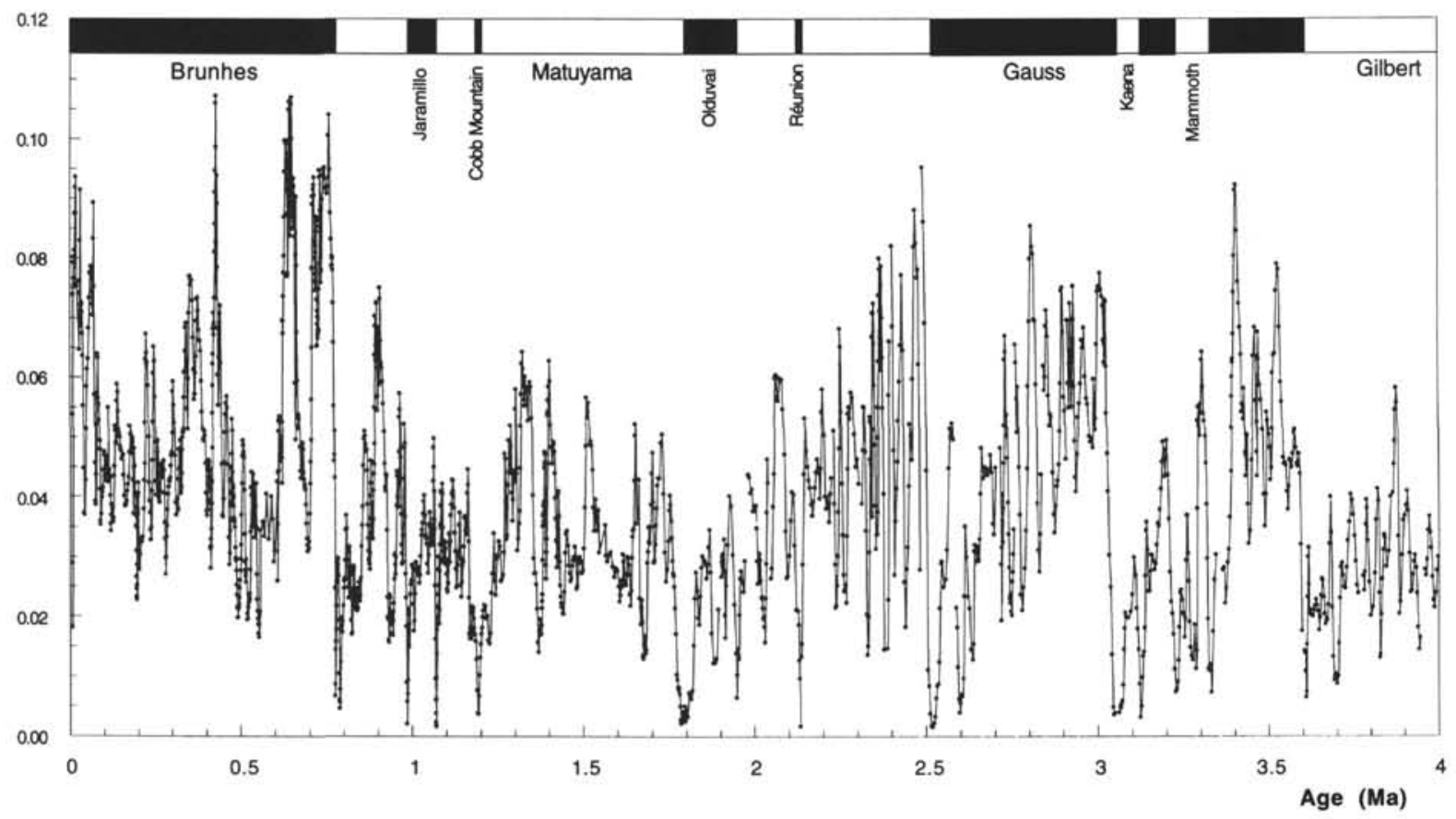

Figure 7. Composite and final record of relative paleointensity for the last $4 \mathrm{Ma}$. The curve is composed of the most detailed parts of the records from Sites 848 and 851.

(possibly the Emperor and/or the Big Lost events). We note that the excursional and the nonexcursional volcanic VDMs show similar low values of intensity. Because the time covered is very large (more than 100 k.y.), it is likely that the nonexcursional VDMs have been disconnected from the excursions and, thus, may represent values of full polarity.

\section{DISCUSSION}

\section{Excursions and Short Polarity Events}

It is interesting to focus our attention first on the most recent part of the record covering the first $1 \mathrm{~m}$.y. In addition to major field decreases associated with field reversals, many other short intervals have significant decreases in intensity. Short intervals with anomalous directions, reflecting either short polarity events or field excursions within the Brunhes, have been reported frequently in the literature. A thorough review of these events with their ages was published by Champion et al. (1988). We compared the average age values given in their compilation with the dates of the significant intensity decreases observed in our record (Fig. 10A). It is striking that the two sets of age values show a perfect linear correlation up to 620 k.y. (Fig. 10B). Beyond this period, the discrepancy results from the differences between the recent ages, deduced from the astronomical values (Shackleton et al., 1990; Hilgen, 1991) used here and the older potassium-argon ages assigned to the Brunhes/Matuyama boundary. Indeed, Shackleton et al. (1990) found that a significantly better match with orbital models was obtained by departing from the previous time scales before $620 \mathrm{k} . \mathrm{y}$. The corresponding offset is reflected in our data set by a jump in Figure 10B between the Big Lost and the Delta events. In their paper, Champion et al. (1988) stated that the reader would have to decide for him/herself whether the process of identification and correlation of events was or was not influenced by the "reinforcement syndrome" of Watkins (1972). We find it difficult to believe that each of the eight polarity subchrons in the Brunhes and two others (Kamikatsura and the Cobb Mountain [Clement and Martinson, 1992]) in the late Matuyama occurred synchronously with low intensity intervals purely by coincidence. These intervals may be characterized by even larger intensity decreases that would not be seen in the present data set for reasons linked to the resolution of the records.

Short events and excursions have also been observed within the $500,000 \mathrm{yr}$ preceding the Brunhes/Matuyama boundary. The Gilsa Event was documented by Clement and Kent (1987) in Hole 609B from the equatorial Atlantic Ocean. The Réunion Event was identified in profiles of marine magnetic anomalies (Heirtzler et al., 1968) and many terrestrial volcanic (McDougall and Watkins, 1973) and sedimentary sections (Tauxe et al., 1989). As noted for the previous events, we did not observe directional changes during these periods, but well-defined zones of low intensity exist (Fig. 10C). Two other short low intensity intervals have also been recently documented by Gallet et al. (1993), who studied the record from Hole 803A in the Ontong Java Plateau (Leg 130). These last two intervals were named Ontong Java 1 and Ontong Java 2 (Gallet et al., 1993).

Champion et al. (1988) noticed that the timing of these events appears to be more or less regular. Indeed, the mean duration of the interval between two events is $120 \mathrm{k}$.y. (with a standard deviation of 50 k.y.) and, thus, is much more constant than between successive reversals. Although the process is clearly not periodic, this result suggests that, for some reason, the geomagnetic field may have experienced low intensity intervals during this period with a characteristic time of the order of 100 k.y.. We do not know whether other excursions or short events occurred during the previous period between 1.5 and $4 \mathrm{Ma}$. The overall pattern of the curve suggests that this may likely have been the case.

These observations are relevant to speculation about the origin of small-scale marine magnetic anomalies (Blakely and Cox, 1972; Labrecque et al., 1977; Cande and Kent, 1992). Cande and Labrecque (1974) suggested that these tiny wiggles are probably not complete reversals of the field, but instead were caused by intensity variations of the paleodipole field. Although the validity of transitional directions recorded by sediments in the presence of a very weak magnetic field can be questioned, the existence of intermediate and reversed directions in volcanic records for at least three of these events (Champion et al., 1988) could argue against this interpretation. Our results, taken with the compilation by Champion et al., suggest that these tiny wig- 

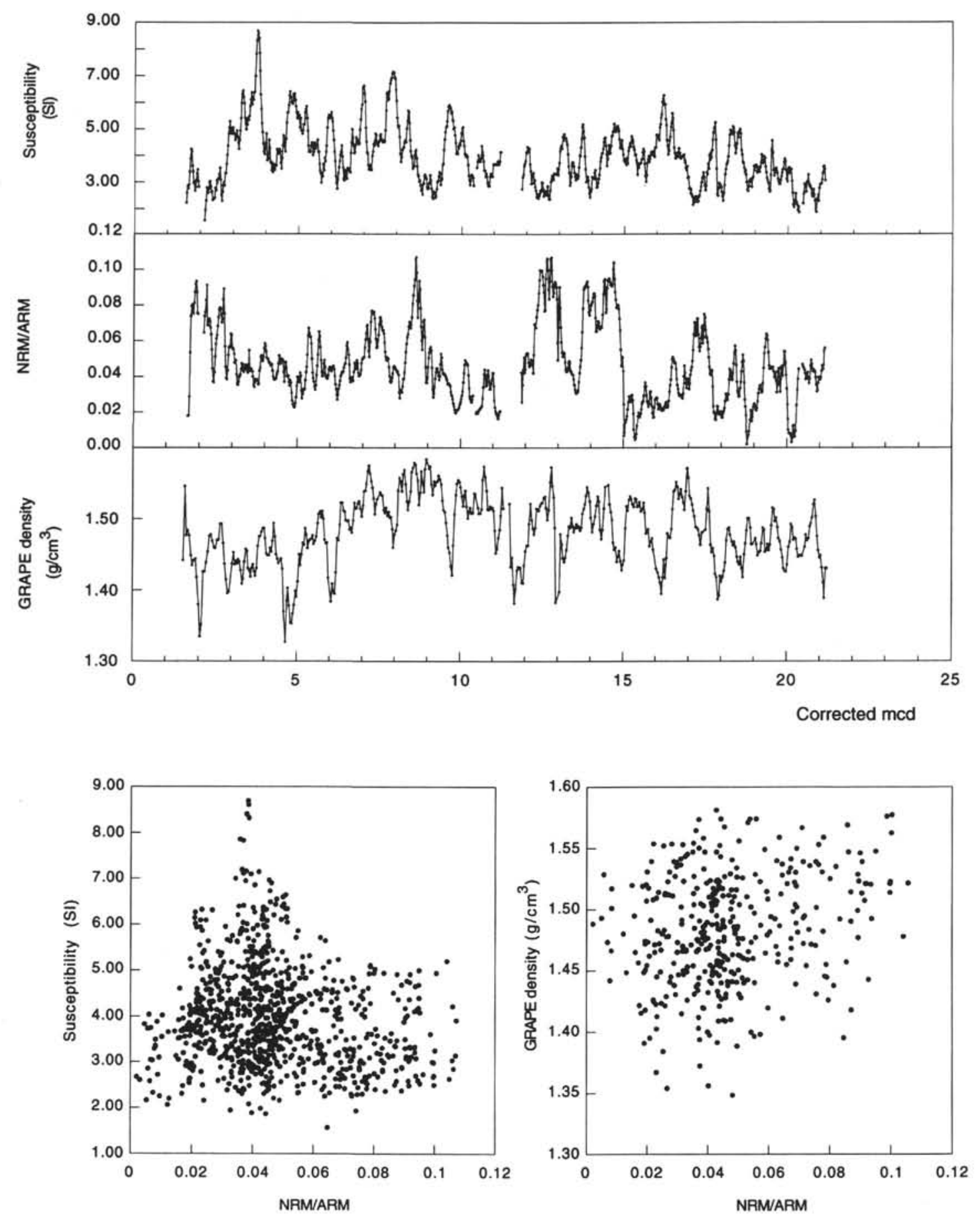

Figure 8. Downhole changes in the low-field susceptibility, $\mathrm{NRM}_{(20 \mathrm{mT})} / \mathrm{ARM}_{(20 \mathrm{mT})}$ and density variations recorded in Hole 851D. No correlation is seen between these parameters, as indicated also by the plots of $K$ and density vs. NRM/ARM.

gles could have been accompanied by very rapid directional changes. However, we note that these changes were not observed in our record because of the low deposition rates and smoothing inherent to the magnetization of sediments. We note also that some other minima were present that do not coincide with previously observed events.

This part of the record can also be compared with other data sets spanning the Brunhes Chron. Three cores were studied from the Ontong Java Plateau (ERDC 89p and 113p; Tauxe and Wu, 1990) and one from the North Pacific (RC10-167; Kent and Opdyke, 1977). The cores from the Ontong Java Plateau were dated using oxygen iso- topes, with the position of the Brunhes/Matuyama boundary defined at $0.73 \mathrm{Ma}$. The core from the North Pacific is the longest record, but was dated by using only the position of the Brunhes/Matuyama boundary and by assuming a constant deposition rate. This core was taken below the carbonate compensation depth and, therefore, no isotope measurements were possible. Using the depth-time model described above, we thus can propose a more detailed stratigraphy for RC10-167 based on the occurrence of the intensity lows; the resulting record is shown in Figure 11. Despite some differences, which might be explained by short variations in deposition rate or by the fact that 


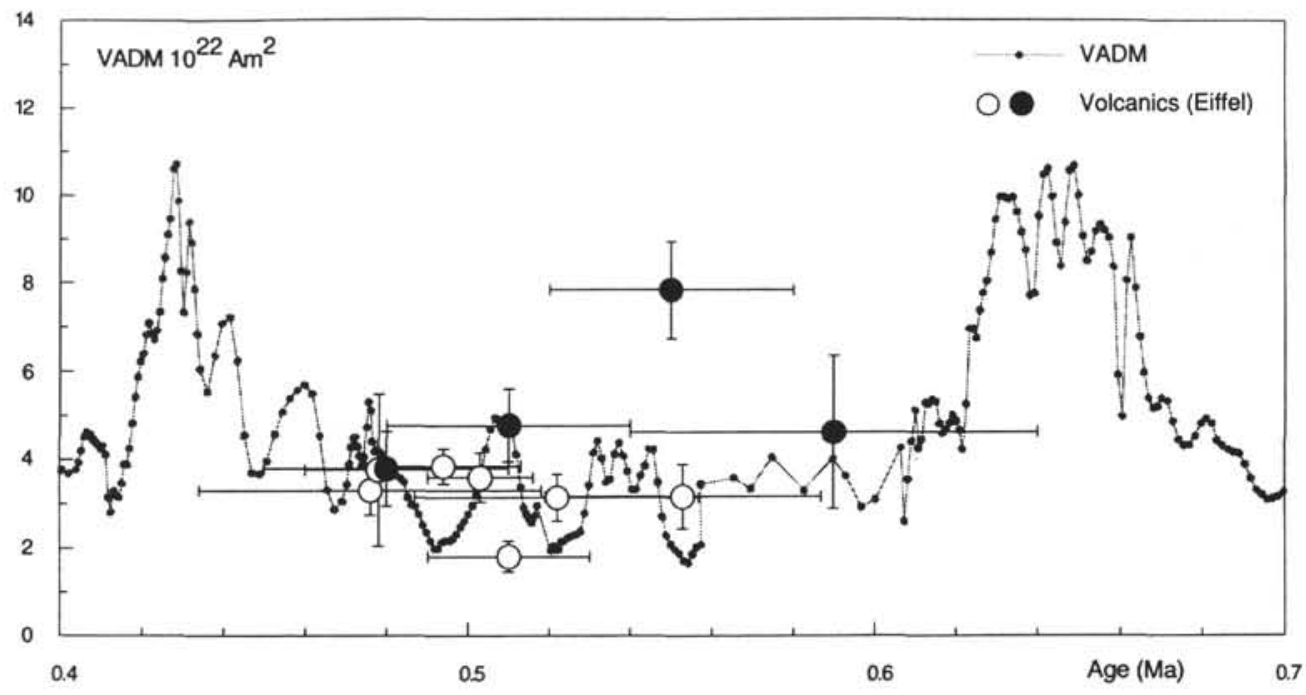

Figure 9. NRM/ARM and NRM/ $K$ values calibrated and converted into VADMs by matching the upper part of the record with the results obtained by Meynadier et al. (1992) in the Indian Ocean for the period 0-140 k.y. A test of this calibration was completed by comparing the record to the absolute VADMs published for the period 0.45 to $0.65 \mathrm{Ma}$ from lava flows of the Eiffel in Germany (Schnepp, 1992, 1994). Closed symbols (opened symbols) = VGP latitude $>45^{\circ}\left(<45^{\circ}\right)$.

this record was obtained $15 \mathrm{yr}$ ago with less accurate techniques of measurements, the agreement between the two curves is relatively satisfactory, especially for the period between $500 \mathrm{k} . \mathrm{y}$. and $1.2 \mathrm{~m} . \mathrm{y}$. Thus, we can conclude that relative paleointensity may be considered seriously as a stratigraphic method.

\section{Field Reversals}

The most impressive feature in our synthetic record of relative paleointensity is linked to the pattern of intensity variations associated with reversals. The evolution in field intensity is asymmetrical, with a gradual decrease before the transitions and a sudden recovery, starting immediately after the directional changes were completed. This typical asymmetrical saw-tooth pattern is particularly visible in the lower part of the record where three successive periods (Gilbert/ Gauss to lower Kaena, Kaena to Gauss/Matuyama (G./M.) and G./M. to Olduvai) are characterized by long-term decreases punctuated by cyclic oscillations (Fig. 12, upper plot). The same process can be observed for the recent reversals (Brunhes/Matuyama, lower and upper Jaramillo and Cobb Mountain), as shown in the lower plot of Figure 12, which gives an enlarged view of this period. The Gauss/ Matuyama boundary being characterized by a complex directional behavior with two successive phases (already observed elsewhere [Liddicoat, 1982]), the limit of this event was taken at the end of the rebound (Fig. 6).

Before going further into the interpretation of these results, we must consider that intensity changes across reversals might result from mixing of magnetic grains with different polarities at the same level. Although such effects must not be underestimated, the present record shows that the long-term field decreases are recorded over varying depth scales that range from 1 to $10 \mathrm{~m}$, which are one or two orders of magnitude larger than the typical depths involved in processes leading to post-depositional reorientations.

The triangular aspect of the intensity pattern between two successive geomagnetic reversals (or events) suggests that a relationship exists between the amplitude of the intensity recovery and the duration of the subsequent field decrease until the occurrence of a reversal. In Figure 13, we plotted the maximum value of the field intensity attained after any given reversal as a function of the duration before the occur- rence of the next event. Both parameters appear to be correlated, with the exception of the interval between the upper Olduvai and the lower Jaramillo. Indeed, no major intensity rebound is seen after this reversal, whereas the time span between the two reversals was as long as 700 k.y.. However, this analysis does not take into account the existence of excursions and/or short events, some of which, such as the Cobb Mountain, have been documented as short polarity intervals. We notice that this discrepancy disappears after incorporating the short events observed in Figure 10C during this period.

The intensity pattern during the Brunhes Chron does not show evidence for a long-term decrease. We note, however, that this is the longest period without reversals appearing in the record. The fact that the present field intensity still remains at a relatively high level is, thus, to some extent, atypical. Another significant difference is that the mean value of the field was significantly higher during this period (Fig. 14). We tentatively speculate that the existence of many successive excursions and/or short events (discussed before) helped to maintain the field intensity during this period.

\section{CONCLUSIONS}

A global aspect of the entire geomagnetic field intensity record can be obtained after filtering the higher frequency components. This calculation has the advantage of removing artifacts that may have been induced by climate changes. Four distinct filters (Fig. 15) were tried successively and yielded the same information. Results confirm that the evolution of geomagnetic field intensity is mostly dominated by two different processes. Rapid field recoveries occur immediately after reversals, with a characteristic time on the order of 10 to $20 \mathrm{k}$.y., and thus are related to the dynamics of core convection (Valet and Meynadier, 1993). These large and sudden changes are immediately followed by a long decline, suggesting a relaxation process having a typical duration in the range of $100 \mathrm{k} . \mathrm{y}$. Between 1.8 to $3.6 \mathrm{Ma}$, the changes in field intensity were dominated by three successive long decreases having a duration of several $100,000 \mathrm{yr}$. These periods occurred subsequent to large field regeneration following major reversals. Superimposed on this main trend, a shorter-term component seems to be present. More detailed analysis is in progress to investigate its origin. The situation was somewhat different during the last 

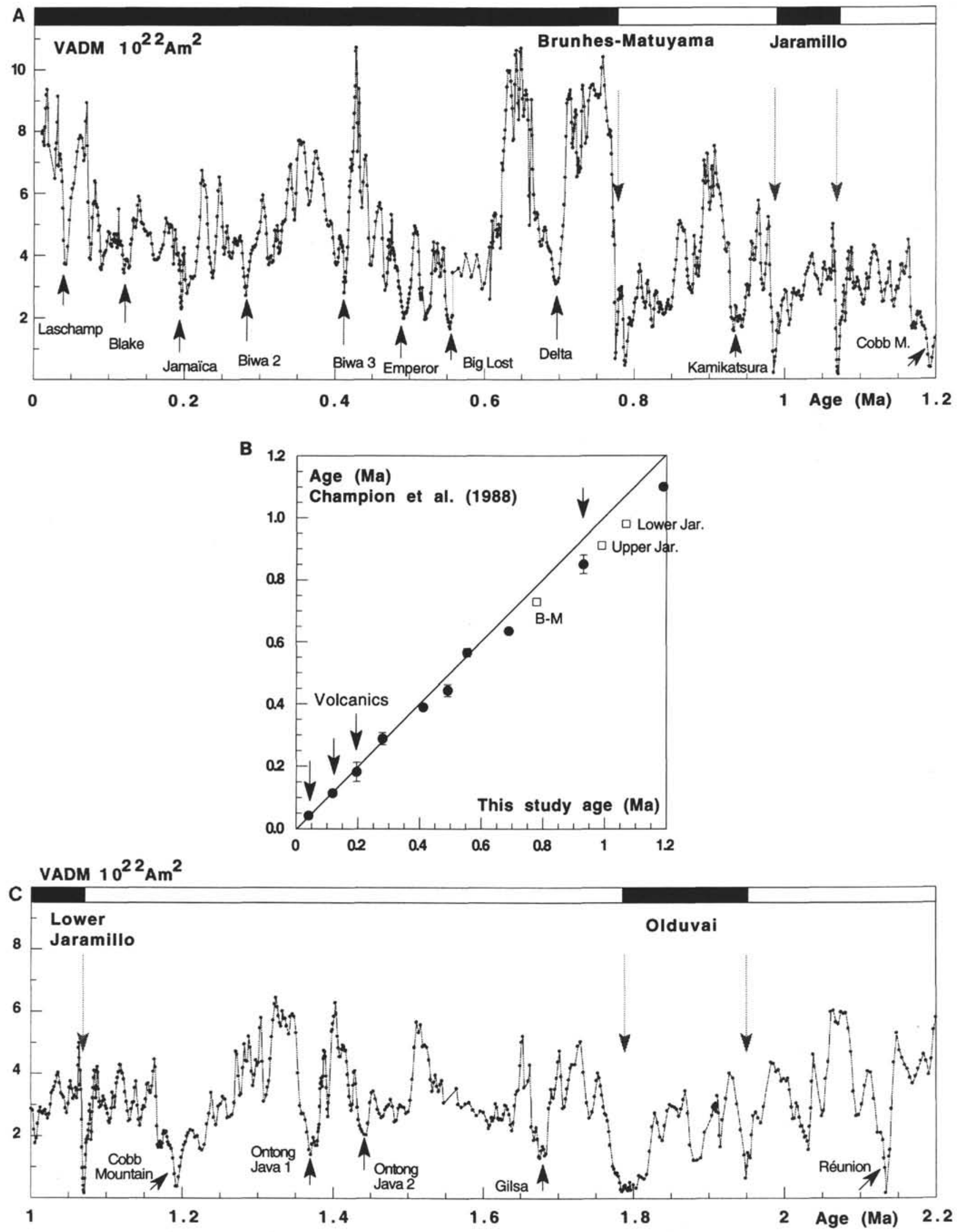

Figure 10. A. Short intervals of intensity lows observed during the period 0 to $1.2 \mathrm{Ma}$. These correspond to dates summarized by Champion et al. (1988) for excursions and/or short events during this period. B. The constant offset beyond $0.62 \mathrm{Ma}$ between the ODP dates deduced from the time-depth correlation and those from Champion et al. is in agreement with the recent recalibration of the polarity time scale (Shackleton et al., 1990). (See text for explanation.) C. Intensity lows of the preceding 1-Ma period compared with excursions and short events. Ontong Java 1 and 2 were observed recently by Gallet et al. (1993) in marine cores from the Ontong Java Plateau. 


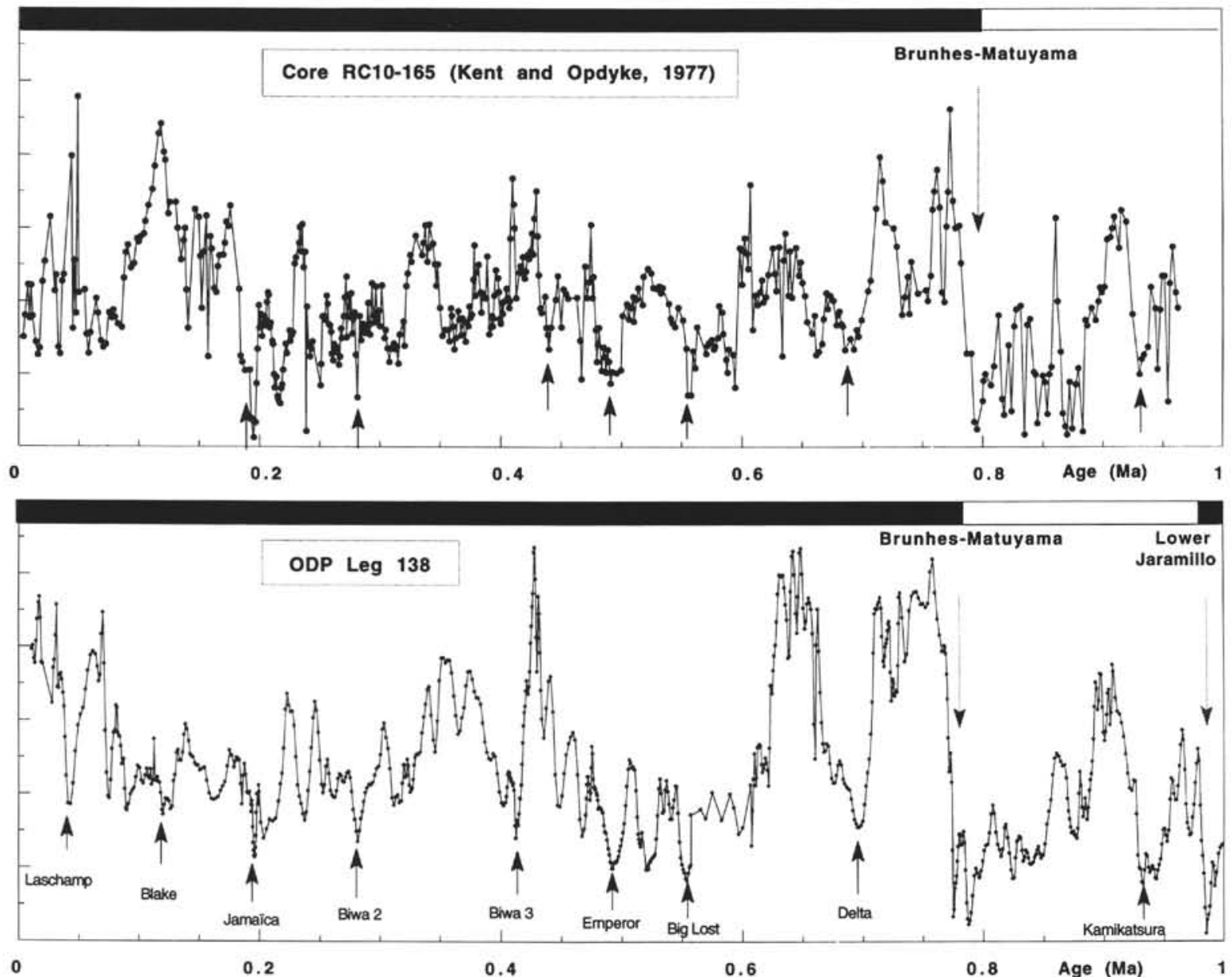

Figure 11. Calibration of the record from Core RC10-167 (North Pacific; Kent and Opdyke, 1977) obtained by correlating the low-intensity events (indicated by arrows) with those observed in this study.

$1.8 \mathrm{~m} . \mathrm{y}$, but the signal remains dominated by the saw-toothed pattern associated with the distribution of the reversals and other geomagnetic events.

We conclude that the regeneration of the geomagnetic field appears to be most significant during brief episodes immediately following reversals or other important geomagnetic events. Whether the amplitude of field regeneration is linked directly to the transitional processes (and the underlying mechanisms) is a critical question. Additional data covering a longer period and detailed volcanic records, including field directions and absolute paleointensity across transitions, should help to answer this fundamental problem.

\section{ACKNOWLEDGMENTS}

The authors are pleased to thank Elizabeth A. Nagy for software developments for measuring the U-channels. Care and time devoted by $\mathrm{T}$. Hagelberg in establishing the composite depths during Leg 138 was greatly appreciated. Many thanks to B. Henry and M. Le Goff at laboratory of Parc Saint Maur for their help with susceptibility measurements. L. Tauxe kindly offered the long core facilities of the paleomagnetic laboratory of Scripps Institution of Oceanography to remeasure some half split cores immediately after the cruise. Stimulating discussions with V. Courtillot, X. Quidelleur, and E. Vincent at different stages of this study were greatly appreciated. The manuscript benefited by thorough reviews by P. Roperch and K. Verosub. This study was supported by the French CNRS INSU ATP Géosciences marines. This is IPGP Contribution No. 1277.

\section{REFERENCES*}

Bassinot, F.C., Beaufort, L., Vincent, E., Labeyrie, L., Rosteck, F., Muller, P.J., Quidelleur, X., and Lancelot, Y., in press. Coarse fraction fluctuations in pelagic carbonate sediments from the tropical Indian Ocean: a 1,500 kyr record of carbonate dissolution. Paleoceanography.

Blakely, R.J., and Cox, A., 1972. Evidence for short geomagnetic polarity intervals in the early Cenozoic. J. Geophys. Res., 77:7065-7072.

Cande, S.C., and Kent, D.V., 1992. Ultrahigh resolution marine magnetic anomaly profiles: a record of continuous paleointensity variations? $J$. Geophys. Res., 97:15075-15083.

Cande, S.C., and LaBrecque, J.L., 1974. Behaviour of the Earth's paleomagnetic field from small scale marine magnetic anomalies. Nature, 247:26-28.

Champion, D.E., Lanphere, M.A., and Kuntz, M.A., 1988. Evidence for a new geomagnetic reversal from lava flows in Idaho: discussion of short polarity reversals in the Brunhes and Late Matuyama polarity chrons. J. Geophys. Res., 93:11667-11681.

Clement, B.M., and Kent, D.V., 1987. Short polarity intervals within the Matuyama: transitional field records from hydraulic piston core sites from the North Atlantic. Earth Planet. Sci. Lett., 81:253-264.

Clement, B.M., and Martinson, D.G., 1992. A quantitative comparison of two paleomagnetic records of the Cobb Mountain Subchron from North Atlantic deep-sea sediments. J. Geophys. Res., 97:1735-1752.

Constable, C.G., 1985. Eastern Australian geomagnetic field intensity over the past 14000 yrs. Geophys. J. R. Astron. Soc., 81:121-130.

\footnotetext{
- Abbreviations for names of organizations and publication titles in ODP reference lists follow the style given in Chemical Abstracts Service Source Index (published by American Chemical Society).
} 
Constable, C.G., and Tauxe, L., 1987. Paleointensity in the pelagic realm: marine sediment data compared with archaeomagnetic and lake sediment records. Geophys. J. R. Astron. Soc., 90:43-59.

Gallet, Y., Gee, J., Tauxe, L., and Tarduno, J.A., 1993. Paleomagnetic analyses of short normal polarity magnetic anomalies in the Matuyama Chron. In Berger, W.H., Kroenke, L.W., Mayer, L.A., et al., Proc. ODP, Sci. Results, 130: College Station, TX (Ocean Drilling Program), 547-559.

Hagelberg, T., Shackleton, N., Pisias, N., and Shipboard Scientific Party, 1992. Development of composite depth sections for Sites 844 through 854. In Mayer, L., Pisias, N., Janecek, T., et al., Proc. ODP, Init. Repts., 138 (Pt. 1): College Station, TX (Ocean Drilling Program), 79-85.

Heirtzler, J.R., Dickson, G.O., Herron, E.M., Pitman, W.C., and Le Pichon, X., 1968. Marine magnetic anomalies, geomagnetic field reversals, and motions of the ocean floor and continents. J. Geophys. Res., 73:2119-2136.

Hilgen, F.J., 1991. Astronomical calibration of Gauss to Matuyama sapropels in the Mediterranean and implication for the Geomagnetic Polarity Time Scale. Earth Planet. Sci. Lett., 104:226-244.

Imbrie, J., Hays, J.D., Martinson, D.G., McIntyre, A., Mix, A.C., Morley, J.J., Pisias, N.G., Prell, W.L., and Shackleton, N.J., 1984. The orbital theory of Pleistocene climate: support from a revised chronology of the marine $\delta^{18} \mathrm{O}$ record. In Berger, A., Imbrie, J., Hays, J., Kukla, G., and Saltzman, B. (Eds.), Milankovitch and Climate (Pt. 1): Dordrecht (D. Reidel), 269-305.

Kent, D.V., and Opdyke, N.D., 1977. Palaeomagnetic field intensity variation recorded in a Brunhes epoch deep-sea sediment core. Nature, 266:156-159.

LaBrecque, J.L., Kent, D.V., and Cande, S.C., 1977. Revised magnetic polarity time scale for Late Cretaceous and Cenozoic time. Geology, 5:330-335.

Liddicoat, J.C., 1982. Gauss-Matuyama polarity transition. Philos. Trans. $R$. Soc. London A, 306:121-128.

McDougall, I., and Watkins, N.D., 1973. Age and duration of the Réunion geomagnetic polarity event. Earth Planet. Sci. Lett., 19:443-452.

Meynadier, L., Valet, J.-P., Weeks, R., Shackleton, N.J., and Hagee, V.L., 1992. Relative geomagnetic intensity of the field during the last $140 \mathrm{ka}$. Earth Planet. Sci. Lett., 114:39-57.

Nagy, E., and Valet, J.-P., 1993. New advances for paleomagnetic studies of sediment cores using U-channels. Geophys. Res. Lett., 20:6/1-6/4.

Schnepp, E., 1992. Paleointensity in the Quaternery West Eifel volcanic field, Germany: preliminary results. Phys. Earth Planet. Inter., 70:231-236.
1994. Determination of geomagnetic palaeointensities from the Quaternary West Eifel volcanic field, Germany. Geophys. J.I., 116:688-714.

Shackleton, N.J., Berger, A., and Peltier, W.R., 1990. An alternative astronomical calibration of the lower Pleistocene time scale based on ODP Site 677. Trans. R. Soc. Edinburgh, Earth Sci., 81:251-261.

Shackleton, N.J., and Shipboard Scientific Party, 1992. Sedimentation rates: toward a GRAPE density stratigraphy for Leg 138 carbonate sections. In Mayer, L., Pisias, N., Janecek, T., et al., Proc. ODP, Init. Repts., 138 (Pt. 1): College Station, TX (Ocean Drilling Program), 87-91.

Stober, J.C., and Thompson, R., 1979. Magnetic remanence acquisition in Finnish lake sediments. Geophys. J. R. Astron. Soc., 57:727-739.

Tauxe, L., LaBrecque, J.L., Dodson, R., and Fuller, M., 1983. "U”'channels-a new technique for paleomagnetic analysis of hydraulic piston cores. Eos, 64:219.

Tauxe, L., and Valet, J.-P., 1989. Relative paleointensity of the earth's magnetic field from marine sedimentary records: a global perspective. Phys. Earth Planet. Inter, 56:59-68.

Tauxe, L., Valet, J.-P., and Bloemendal, J., 1989. Magnetostratigraphy of Leg 108 advanced hydraulic piston cores. In Ruddiman, W., Sarnthein, M., et al., Proc. ODP, Sci. Results, 108: College Station, TX (Ocean Drilling Program), 429-439.

Tauxe, L., and Wu, G., 1990. Normalized remanence in sediments of the Western Equatorial Pacific: relative paleointensity of the geomagnetic field? J. Geophys. Res., 95:12337-12350.

Tric, E., Valet, J.-P., Tucholka, P., Paterne, M., Labeyrie, L., Guichard, F., Tauxe, L., and Fontugne, M., 1992. Paleointensity of the geomagnetic field during the last 80,000 years. J. Geophys.Res., 97:9337-9351.

Valet, J.-P., and Meynadier, L., 1993. Geomagnetic field intensity and reversals during the past four million years. Nature, 336:234-238.

Watkins, N.D., 1972. Review of the development of the geomagnetic polarity time scale and discussion of prospects for its finer definition. Geol. Soc. Am. Bull., 83:551-574.

Date of initial receipt: 29 March 1993

Date of acceptance: 24 January 1994

Ms 138SR-149 

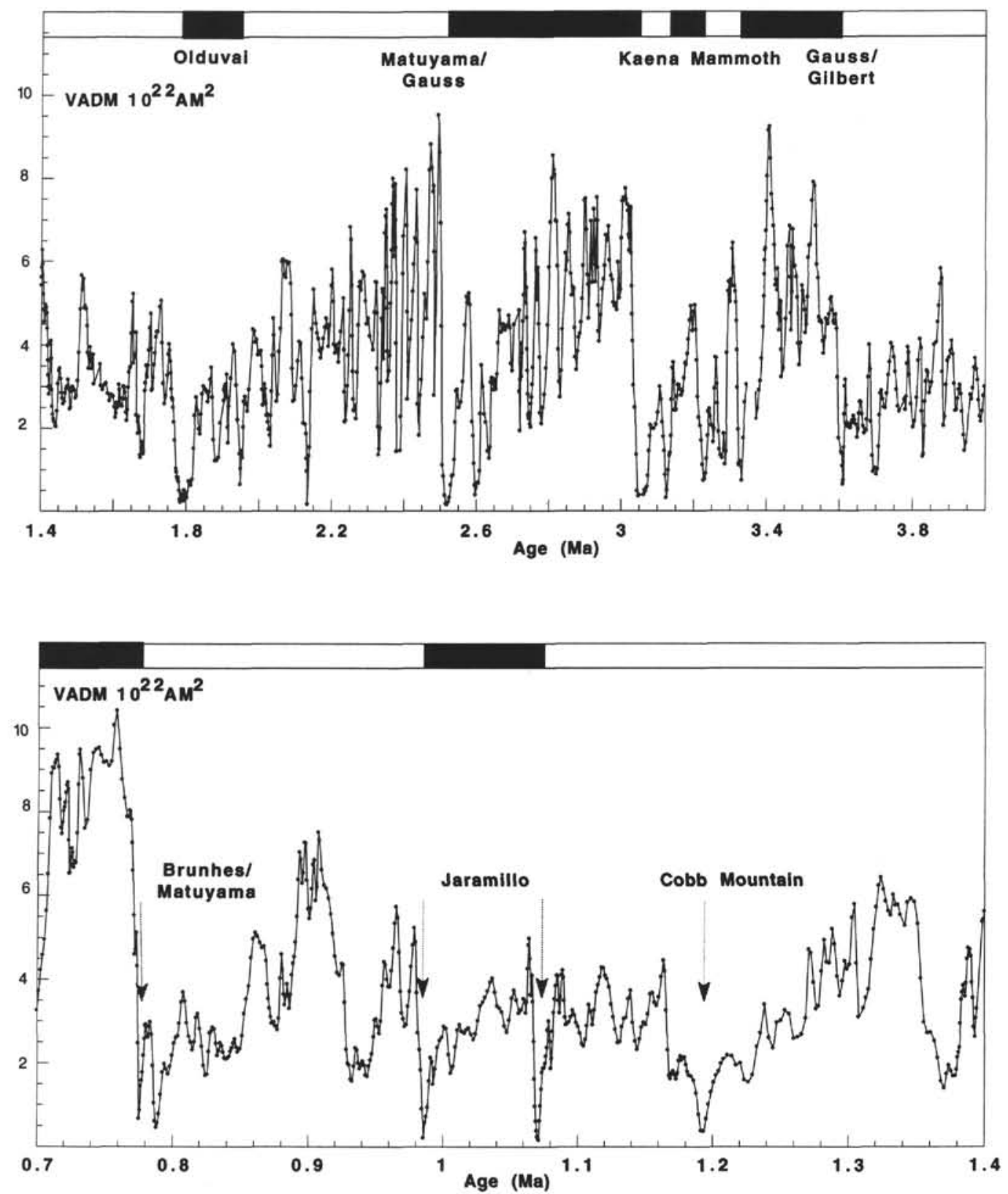

Figure 12. Relative variations in dipole field intensity for the periods 1.4 to $4 \mathrm{Ma}$ and 0.7 to $1.4 \mathrm{Ma}$. The intensity variations display similar asymmetrical saw-tooth patterns across each reversal: sudden and large field recoveries immediately after the transitions followed by long-term decreases. 


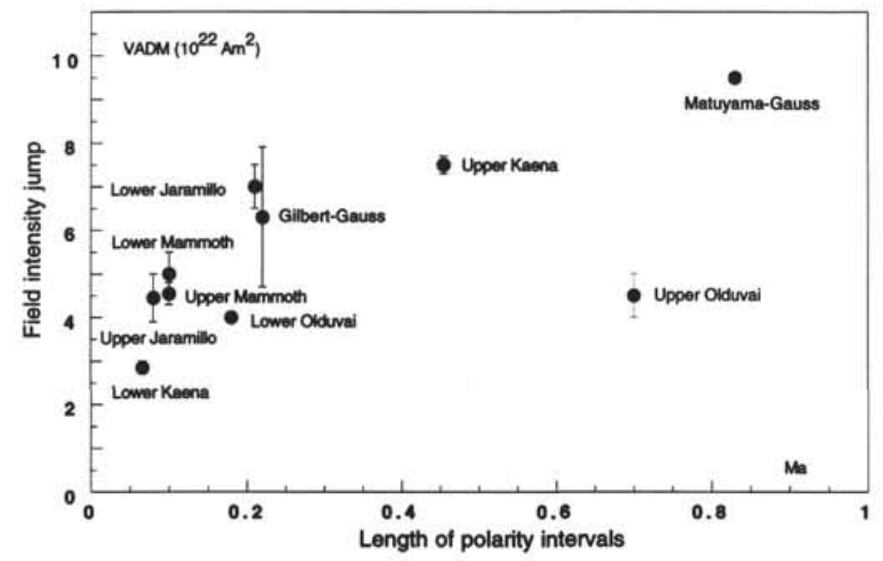

Figure 13. Correlation between the intensity of field recovery after reversals and the duration of subsequent polarity intervals. The upper Olduvai stands out of the main trend (see text for explanation).
A

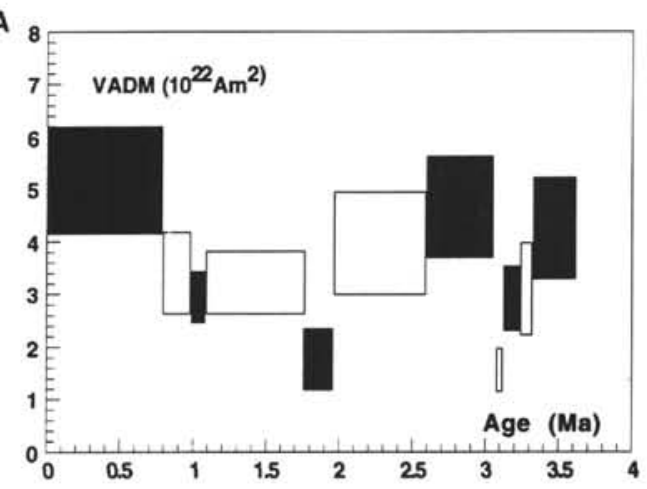

B

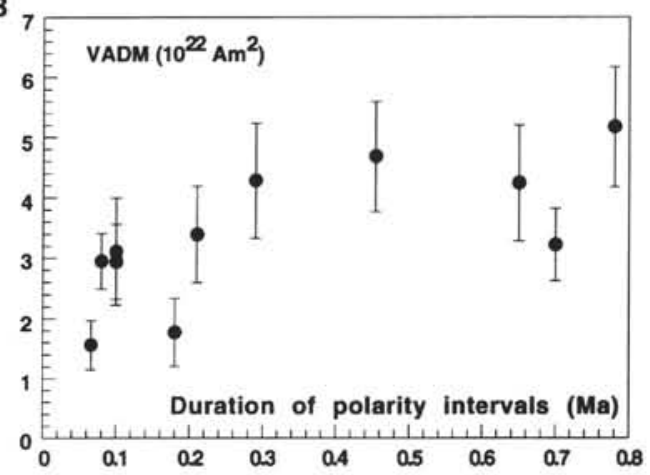

Figure 14. A. Virtual dipole moments (VADMs) averaged per polarity interval. Black (white) rectangles are for normal (reversed) polarity intervals. Mean value of field intensity over the interval is the medium height of the rectangles; their total height represents the standard deviation. B. VADMs averaged per polarity interval as a function of the duration of the polarity interval. The principal outlier is the interval from the upper Olduvai to the Jaramillo onset (see text).

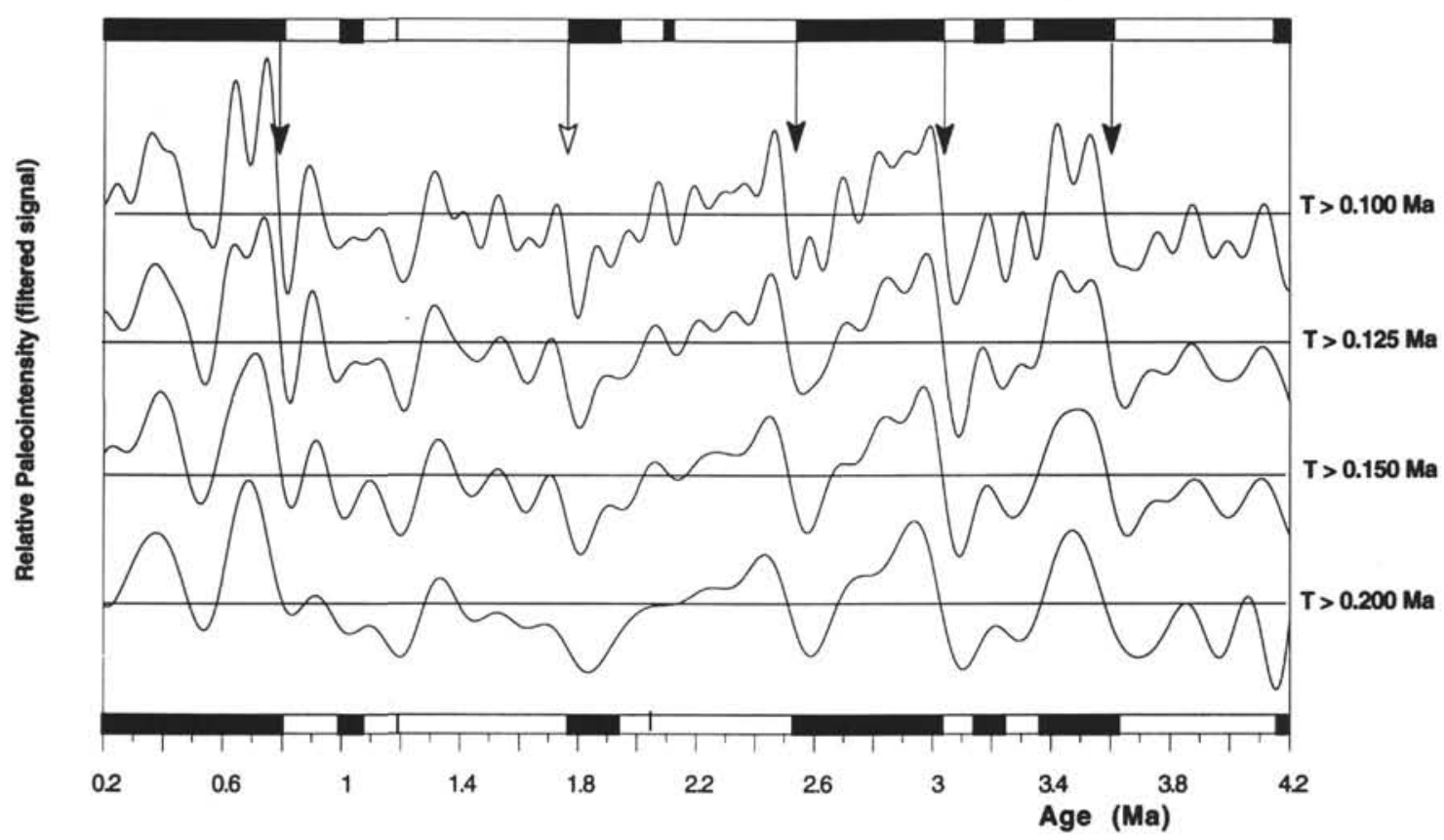

Figure 15. Paleointensity record obtained after filtering the high-frequency components. This procedure removes most of the artifacts that may have been induced by climate changes. This figure gives an overview of the successive patterns identified in the evolution of the signal. Major intensity changes are connected to the corresponding boundaries by black arrows. Atypical pattern linked to the upper Olduvai is indicated by a white arrow. 